\title{
Templates from syntax to morphology: affix ordering in Qafar
}

Pierre Rucart

Université Paris 7 Denis Diderot, France

https://doi.org/10.36505/ExLing-2006/01/0047/000047

\begin{abstract}
The functional head suggests that verbs acquire their inflectional properties by moving from one head position to the next in the syntactic derivation. A problem arises as affixes' ordering is not sensitive to syntactic properties, as it is the case in Qafar. This Cushitic language exhibits two verbal classes depending on whether verbs can have prefixes. I argue that the hierarchical structure of template corre-sponds to the syntactic structure. Phonological constraints on templates formation activate adequate syntactic operations. If we assume that templatic domains lie at the interface between syntax and phonology, we account for some issues of affix order-ing, that involve no syntactic property.
\end{abstract}

\section{Introduction}

In this paper, I suggest an approach of the interface between morphology and syntax in order to explain affixes ordering that are not sensitive to syntactical properties.

First, I present the verbal morphology in Qafar and the templatic representation of verbs. Then I will argue that phonological constraints interact with the syntactical derivation in order to account for the order of affixes.

\section{Verbal classes in Qafar}

The inflectional morphology of verbs in Qafar exhibits two verbal classes: on the one hand weak verbs that have only suffixes and strong verbs that have prefixes and suffixes (cf. Hayward 1978, Parker \& Hayward 1985).

The position of inflectional markers around weak and strong verbs can be represented as follow in table 1:

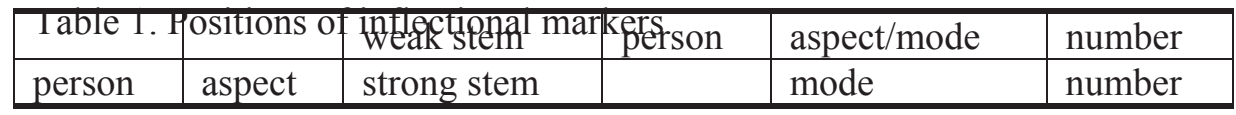

The examples of the weak verb dunqe 'push' and the strong verb uktube 'write' can illustrate these positions. The marker/t/ of second person is a prefix in t-uktube 'you wrote' and a suffix in dunuq-t-e 'you pushed'.

ExLing 2006: Proceedings of 1st Tutorial and Research Workshop on Experimental Linguistics, 28-30 August 2006, Athens, Greece 
Imperfect is marked by the suffix /a/ in dunqa 'you push' versus dunqe 'you pushed'. In strong verbs, this marker /a/ is at the left edge of the stem as in $a$-ktube 'I write' and $a$-cfide 'I learn'. This /a/ alternates with the initial vowel that is always a copy of the vowel stem in perfect: $u$-ktube 'I wrote' and $i$-cfide 'I learnt'. I assume that the suffix /e/ in the perfect and imperfect forms of strong verbs cannot appears in the imperfect forms of weak verbs because hiatus are prohibited in Qafar. If both markers /e/ and /a/ are in successive position, only one is phonetically realized (cf. Rucart 2000).

The suffix /e/ alternates with the suffix /o/ to express a modal distinction with purposive that is dunq-o 'that I push' and aktub-o 'that I write'. Again, in weak verbs, the marker /o/ cannot be realized at the same place as the aspectual marker /a/.

The plural marker $/ \mathrm{n} /$ is the last suffix in both classes as in dunqten 'you pushed-plural' and tuktuben 'you wrote-plural'.

\section{Verbal template}

The examination of strong verbs shows that they have trilateral roots. In case of the lack of one consonant, one can observe a vocalic lengthening. Facing the triliteral verb uktube 'write', there is verbs like egeere 'bail' or eexge 'know', with a long vowel in the stem. Additional consonant are always derivational onto express passive or causative for example.

These can be prefix consonant like in $u$-s-kutube 'make s.o. write', internal geminate like usku-tt-ube 'be written' or suffix like uktubute 'write for oneself'.

Then I propose that strong verbs share a unique template with three root consonant positions and three derivational positions (in brackets below) within the Government Phonology - CVCV option theory (cf. Rucart 2002). The following template allows us to represent every strong verb stem:

(CV) $\mathrm{CV}(\mathrm{CV}) \mathrm{CV} \mathrm{CV}(\mathrm{CV})$

I assume that weak verbs share the same template. Most of them are triliteral and can have an internal germination or a consonant suffix like in dunnuqime 'be pushed'. Moreover the passive of weak verbs with two root consonants (like fake 'open') have a final geminate in association with an unexpected following long vowel like in fakkiime 'be opened'. If no underlying can be invoked to explain this vocalic lengthening, we can assume that it is an effect of the underlying template. This template with three root consonant positions has to be identified.

\section{Initial CV and Proper Government}

Lowenstamm (1999) propose that template of al major category have an initial CV at their left edge. Like every other nucleus, the $\mathrm{V}$ position of the ini- 
Templates from syntax to morphology: affix ordering in Qafar 215

tial CV has to be either phonetically interpreted, either properly governed to remain empty. An empty position is properly governed only if the following nucleus is phonetically interpreted.

Now, the position of the lexical vowel in weak verbs and strong verbs is different in the template. The lexical vowel of weak verbs is always between the two first root consonants whereas the lexical vowel of strong verbs is between the second and the third consonants.

Thus, the initial CV of weak verbs is always properly governed by the lexical vowel and can remain empty. In the case of strong verbs, the nucleus between the two first consonant is empty and the preceeding nucleus, in the initial CV position, cannot remain empty. The two configurations are represented in table 2 below:

Table 2. Initial CV and Proper Government

\begin{tabular}{|l|c|}
\hline weak verb & $\mathrm{C} V-\mathrm{R}_{1} \mathrm{~V}_{\mathrm{LEX}} \mathrm{R}_{2} \varnothing \mathrm{R}_{3}$ \\
$\uparrow$ & $\mathrm{PG}$ \\
\hline strong verb & $\mathrm{C} \mathrm{V}-\mathrm{R}_{1} \varnothing \mathrm{R}_{2} \mathrm{~V}_{\mathrm{LEX}} \mathrm{R}_{3}$ \\
& $\uparrow / / /{ }^{*} \mathrm{PG}$ \\
\hline
\end{tabular}

In the next section, I will show how this difference is crucial to understand the difference of the inflectional morphology of the two verbal classes.

\section{The interface between syntax and phonology}

I assume that the templatic structure corresponds to the syntactic structure: the syntactic constituents correspond to templatic domains that share the same hierarchical structure. As far as phonological segments are linked to this template, I argue that the templatic representation of the morphological level is an interface between syntax and phonology.

Following the functional head approach (Pollock 1989), verbs acquire their inflectional properties by moving from one head position to the next during the syntactic derivation. But, in Qafar, affix ordering is not sensitive to syntactic properties (Stump 1998). I propose that constraint on the wellformedness of templatic domain of the interface interact with syntactic movements.

If the template is well-formed as it is the case for weak verbs in which the initial CV is properly governed, then the verb head move to the inflectional head, and personal and aspectual markers are suffixed to the verbal template:

In strong verbs, the initial $\mathrm{CV}$ is not properly governed: the template is not well-formed. Consequently, the verbal head is directly adjoined to the inflectional head in order to solve the conflict. Then, inflectional marker 
come at the left edge of the template and can identify the initial CV. This position doesn't need to be properly governed any longer.

\section{Conclusion}

If we assume that templatic domains lie at the interface between syntax and phonology, we account for some issues of affix ordering, that involve no syntactic property.

\section{References}

Hayward, R.J. 1978, The prefix conjugation in Afar, in Atti del secondo congresso internazionale di linguistica Camito-Semitica, Fonzaroli, P. (eds.), Firenze, Universita di Firenze.

Kaye, J., Lowenstamm, J., Vergnault, J.R. 1990, Constituent structure and Government Phonology, in Phonology Yearbook 7.

Lowenstamm, J. 1996, CV as the only syllable type, in Durand, J. and Laks, B.. (eds.) 1996, Current trends in Phonology, Salford, Manchester, E.S.R.

Lowenstamm, J. 1999, The beginning of the word, in Phonologica 1996, Rennison \& Kühnhammer (eds.), The Hague, Holland Academiv Graphics.

Parker, E.M., Hayward, R.J. 1985, An Afar-English-French dictionary, London, S.O.A.S.

Pollock, J.Y. 1989, Verb movement, universal gammar and structure of the IP, in Linguistic Inquiry 20:3.

Rucart, P. 2000, Aspect de la morphologie verbale de l'Afar, D.E.A. dissertation, Paris, Université Paris VII

Rucart, P. 2002, The vocalism of stong verbs in Afar, in BLS 27S Afroasiatic Linguistics, USA, Berkeley.

Stump, G.T. 1998, Inflection, in The handbook of morphology, Spencer \& Zwicky (eds.), London, Blackwell. 